\title{
Development and Implementation of an Electric Circuits On-Line Course
}

\author{
doi:10.3991/ijoe.v5i1.745 \\ M. M. Dawoud, H. Al-Jamid, N. Tasadduq, A. Hussein, and U. Johar \\ King Fahd University of Petroleum \& Minerals, Saudi Arabia
}

\begin{abstract}
An electric circuit on-line course has been developed at KFUPM to support student centered learning. The course has been used in the first stage to supplement the class room face-to-face instruction. This paper describes the development stages of the on-line course and highlights its fundamental features that are not available in the traditional methods of instruction. The paper also includes the results of a survey conducted among students who have utilized the on-line material to supplement their traditional study of the electric circuits' course. The results of the survey showed a general satisfaction with the course content and the instructional effectiveness.
\end{abstract}

Index Terms-Animation, Electric Circuits, Multimedia, Online Course, Interactivity.

\section{INTRODUCTION}

Academic establishments and universities have been working for many years on the development and preparation of its courses to be delivered on the Internet. The advantages of on-line instruction are recognized and well established. E-learning is naturally suited to distance learning and flexible learning. It can also be used in conjunction with face-to-face learning. This is referred to as a blended mode of learning [1]. Many technologies are used in E-learning such as communication tools (e-mail, chat, discussion forums), learning management software, multimedia CD ROMs, and many others. Key advantages of e-learning are flexibility, convenience and the ability to work at any place where an internet connection is available and at one's own pace. Like other universities worldwide, KFUPM has started the development of online courses to be utilized on and off campus [2]. In this paper we present the stages followed in the development of an electric circuits, on-line course. The course is used by the sophomore students majoring in Electrical Engineering.

\section{COURSE MATERIAL}

The material covered in the e-course was based on textbook and syllabus coverage used in the classic face to face classroom lectures. The classic material coverage was adapted to make it suitable for an online course, while insuring a rich and complete coverage of the material. Care was exercised to balance the content and maintain continuity of each lecture, whenever possible. The ecourse consists of 36 lectures which are divided into the following 7 modules:

1. Introductory Concepts

2. Circuit Analysis Techniques
3. Thevenin's and Norton's Equivalent Circuits

4. The Operational Amplifier

5. Energy Storage Elements and First Order Circuits

6. Sinusoidal Circuit Analysis

7. Power in Sinusoidal Circuits

The course material contains many examples, graphics and animations. All these were also supported by speech. The necessary speech files were generated using a Textto-Speech software tool.

A self test is included at the end of each lecture, for the purpose of self assessment by the student. A student can try out the self test and can get an immediate feedback. A multiple choice quiz is also included at the end of each module, which can be used by the student for the purpose of self assessment. Some lectures also include speech supported interactive electric circuits that are designed for enhanced understanding of important concepts. The student can run the interactive circuit, change its parameters through a slider (or a button), and observe the change in circuit behavior.

\section{Development Of The OnLine Course}

The development of the on-line course was carried out by a team which comprised of two subject matter experts, and three graphics designers and content developers. The development progressed in several stages [3], [4] as described below:

\section{A. Preparation of Course Content}

The subject matter experts prepare the course material using Microsoft Office, Math-Type and Visio. The entire course is then developed by the graphics designers for elearning using Macromedia Authorware as an authoring tool which allows the publishing of course lectures in HTML format for delivery over the internet [5][6][7]. The course material is enriched with audio, animations and interactive examples.

Phase I-Transfer of Course Material to Authorware: This involves preparation of course contents in electronic format (e.g. MS Word) especially tailored for online delivery The course material is prepared based on a text book and the experience of the subject matter experts in teaching this course in a traditional face-to-face class.. The prepared material is transferred from MS Word format to Macromedia Authorware.

Phase II - Animations \& Embedding of Speech Files: In this phase, animations are added and audio files are generated for each lecture. Animations are designed to make the presentation more attractive and help students 
understand quickly concepts and ideas presented. The audio files are embedded in the Authorware files and synchronized with the flow of text and animations on each slide.

Phase III - Refinement of Lectures \& Interactivity: This is an important phase in which each lecture is reviewed by the team for improvement of the material in all its aspects and its overall presentation. The lectures are then modified based on the comments/suggestions made in the review. Interactive examples/circuits suggested for a lecture, as a result of the review, are also implemented.

Phase IV - Publishing of Lectures for WebCT: Each lecture is published in HTML format using the built-in publishing tool in Authorware. The published lectures are uploaded to the EE 200 course shell in WebCT and then hyper-linked and organized under modules. Other documents related to the course are also made available on the WebCT.

\section{B. Generation of Speech Files}

An Automatic Text-to-Speech software tool [8] was used to generate the audio speech files. This Automatic Text-to-Speech tool provides great flexibility in the creation and maintenance of speech files for lectures with speech embedded in them. It allows the speech files to be generated from text very easily. Any time a speech file needs to be changed only the text file is modified and a new speech file is created easily.

\section{Assessment of Students}

For the purpose of student assessment, the online course features a set of quizzes and assignments. The type of questions that can be setup for quizzes and exams is limited. Some questions in quizzes and exams that require students to enter mathematical equations, design a circuit, etc. are not possible with the existing tools and hence cannot be offered online. Such quizzes and exams have been offered offline in the traditional manner.

\section{Communication Tools}

WebCT offers a comprehensive set of communication tools facilitating student-to-student cooperation, studentto-instructor interaction, and group discussions. Both synchronous and asynchronous communication tools, like Chat, White Board, Discussions, e-mail, etc. are available in WebCT and the same are fully utilized in this online course. Besides these tools, students were also able to contact their instructors by phone. Contact information like email addresses, phone numbers of instructors, schedule of instructors' contact hours are posted on the website.

\section{E. Management Tools}

The following management tools are available as builtin features under WebCT platform that are utilized in the management of the online course:

- Course Material Delivery: control of release of materials on time basis such as course syllabus, lectures, quizzes and homework.

- Student Tracking: by the instructor to assess his utilization of the online material.

- Student Progress: allows students to access his grades and compare his performance with the class average.

\section{INTERACTIVITY AND MULTIMEDIA FEATURES}

One of the most important advantages of an online course is having the ability to incorporate interactivities. This involves the students more to create an active learning environment, which is widely believed to result in better learning. This can be achieved by well designed interactive examples, which will enhance student participation and will arouse his interest in the subject. Learning can also be enhanced through the feedback that interactive examples give to the students. Experience also shows that difficult to understand concepts in a face-toface class or which take longer for an instructor to explain in the class are easily understood by way of interactive examples.

Knowing this the team prepared many interactive circuits which allow the students to interact with the circuit, change parameters and monitor the resulting effects. We have incorporated in this course interactive circuits and examples covering the following topics:

- Open and Short circuit concepts

- Ohm's Law

- Kirchhoff's Current Law

- Current and Voltage Division Rule

- Voltage to Current Source Transformation

- Current to Voltage Source Transformation

- Maximum Power Transfer

- Natural Response

- Step Response

- Impedance of Inductors and Capacitors

- Phase Shift Concept in Sinusoidal Circuits

\section{A. Sample Interactive Examples from the Online Course} Material

In this online course, topics that are difficult to comprehend by students are made far easier to understand by utilizing animated explanations and examples. To quote an example, application of KVL using clockwise direction or anticlockwise direction is illustrated by using animated arrows. Similarly Source Transformation, Superposition, Nodal Analysis, Mesh Analysis etc. are discussed by utilizing animated circuits.

Fig. 1 shows interactive circuit for Ohm's Law. A student can change the voltage as well as the resistance values using the slider. Current will be automatically calculated and displayed as the student changes the values. If the student selects the two extreme values of resistance i.e. short circuit and open circuit, a warning is displayed indicating that this may result in an invalid circuit, depending on the source used.

Fig. 2 demonstrates the concept of maximum power transfer. The student is requested to vary the value of a resistor and monitor the resulting change in the power delivered to this resistor. At a given value of the resistor, the maximum power transfer will occur. The power will be calculated and displayed in real time, with the location identified on a graph.

Fig. 3 illustrates the concept of time constant and the natural response of an RC circuit. In this interactivity the student will select the value of a resistor by using a selection button and trigger the circuit by opening a switch. The student will monitor how the capacitor will 
discharge. The time constant will be also calculated and displayed along with a graph. The time required to plot the graph is proportional to the actual calculated time constant of the RC circuit.

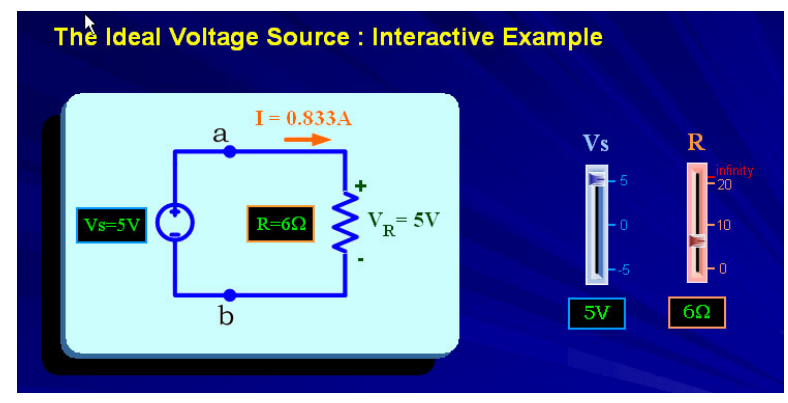

Figure 1. Interactive example on Ohm's Law
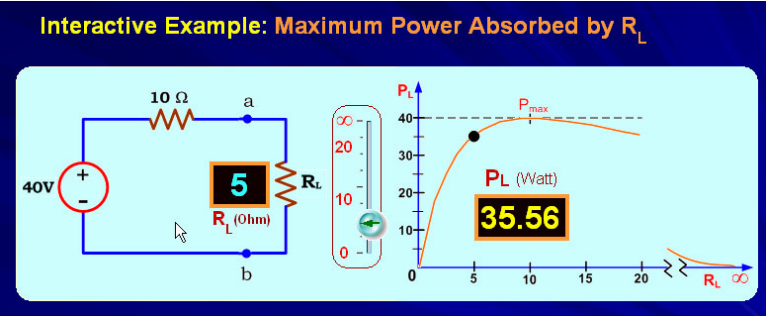

Figure 2. Interactive example on Maximum Power Transfer

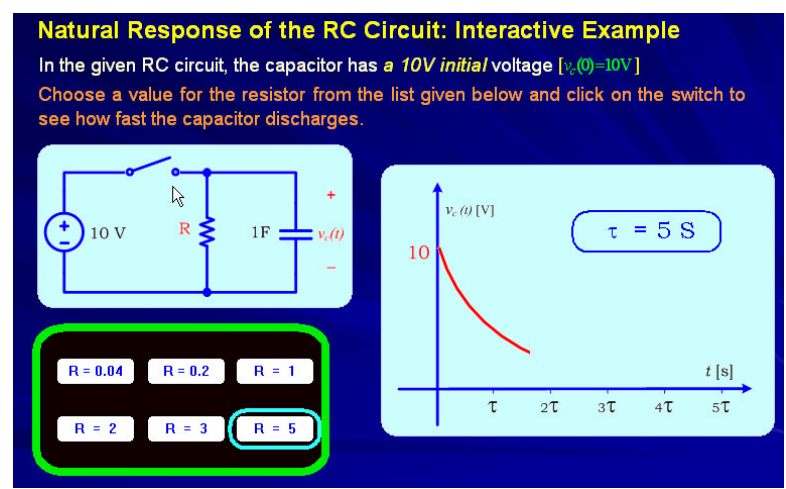

Figure 3. Interactive example on Maximum Power Transfer

\section{STUdENTS’ SURVEy RESUltS}

A survey was conducted for the purpose of the student evaluation of the online course EE 201 that has been offered to students in two consecutive semesters in 2005/06. The survey was designed to measure the clarity and effectiveness of the online course with a total of 26 questions. The aspects of the online course that the students were asked to rate include course information, course content, web and multimedia, course activities and interactivity and student motivation and comments. Results of the survey are highlighted here. The online course material was delivered as supplementary resource to face to face teaching throughout the academic year while some of the lectures were conducted using the online material without formally covering them in class. The aspects rated highest are the clarity of overall course objectives, helpfulness of examples in understanding and sufficient number of multimedia elements. The aspect rated lowest is the number of learning resources and clarity of text and graphics. Some of the lectures from the online course were used to replace the lectures in the classroom and were not formally discussed, so the mode used is blended one. 42 students amounting to less than $30 \%$ of the total number filled the survey. Students appreciated the web-based based instruction. In addition, they have pointed out some strengths and weaknesses of the online course. An example of the response of the students to questions regarding the course content is shown in Fig. 4. The mean rating is 3.908. The response to questions regarding the instructional effectiveness has a mean rating of 4.036 and is given in Fig. 5.

The survey showed that there is a general satisfaction with the course content and the instructional effectivness. Dissatisfaction concentrated mainly on the accessability of the on-line material off campus.

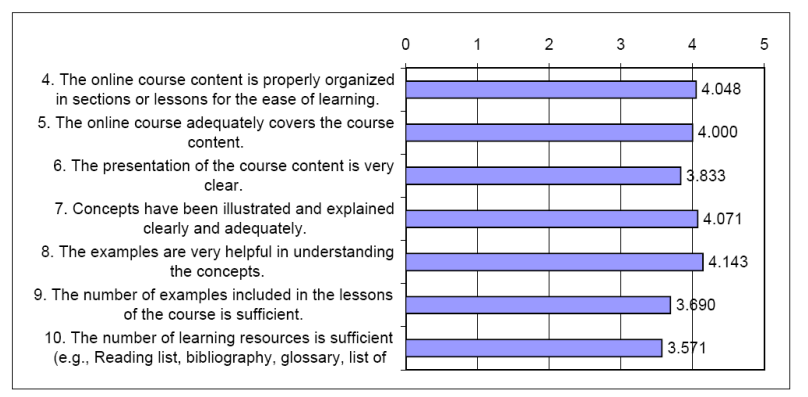

Figure 4. Response of students to questions regarding the course content ranging from (5) strongly agree to (0) strongly disagree.

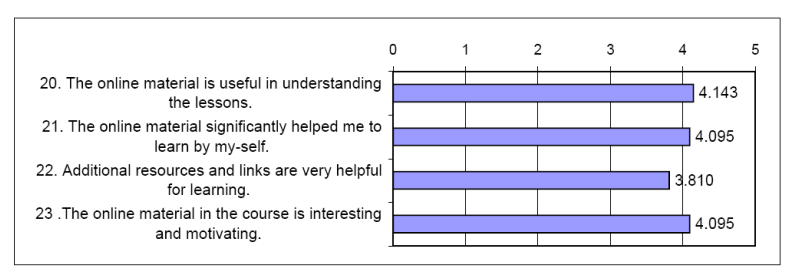

Figure 5. Response of students to questions regarding the Instructional effectiveness, ranging from (5) strongly agree to (0) strongly disagree.

\section{CONCLUSION}

The developed on-line course has been effective in illustrating the fundamentals of electric circuits in a way that is not possible in the traditional face-to-face mode of teaching. Full use of multimedia capabilities including interactivity has helped the students' learning process. Surveys conducted among the students revealed that they appreciated the clarity of overall course objectives, and the usefulness of examples for understanding. In addition number of multimedia items, online material usefulness in understanding the lessons, and organization of course content is also appreciated.

\section{ACKNOWLEDGMENT}

The authors acknowledge the support of King Fahd University of Petroleum \& Minerals and the Deanship of Academic development in conducting this project.

\section{REFERENCES}

[1] Electronic Learning, http://en.wikipedia.org/wiki/E-learning.

[2] M. Mohandes, M. Dawoud, A. Abul Hussain, S. Al Amoudi, "Online development of digital logic design course", 2nd IEEE International Conference On Information \& Communication Technologies: From Theory To Applications, April 2006. 
[3] How to Develop an Online Course, http://stylusinc.com/ online course/tutorial/process.htm.

[4] W. Horton, Designing Web-Based Training, John Wiley \& Sons, 2000.

[5] Using Authorware, Macromedia, Inc., 600 Townsend St. San Francisco, CA 94103, First Edition, August 200.

[6] S. Junaidu and J. Al-Ghamdi, "Developing an online data structures course using authorware”, USDLA Journal, vol. 16, no.10, October 2002. http://www.usdla.org/html/journal/ OCT02 Issue/article07.html

[7] A Guide for Course Developers, Deanship of Academic Development, KFUPM.

[8] TTS (Text-To-Speech) Software, AT\&T Bell Labs, http://public.research.att.com/ ttsweb/tts/

\section{AUTHORS}

M. M. Dawoud, H. Al-Jamid, N. Tasadduq, A. Hussein, and U. Johar are with the Electrical Engineering Department, King Fahd University of Petroleum and Minerals, Dhahran 31261, Saudi Arabia (email: mmdawoud@kfupm.edu.sa).

This work was supported by the Deanship of Academic Development, King Fahd University of Petroleum \& Minerals, Dhahran, Saudi Arabia.

This article was modified from a presentation at the International Conference of Interactive Computer Aided Learning ICL2008, September 24 - 26, 2008 in Villach, Austria. Manuscript received 01 December 2008. Published as submitted by the authors. 